\title{
Human thrombopoietin knockin mice efficiently support human hematopoiesis in vivo
}

\author{
Anthony Rongvaux ${ }^{a, b}$, Tim Willinger ${ }^{a, b}$, Hitoshi Takizawa ${ }^{b, c, d}$, Chozhavendan Rathinam ${ }^{a, b}$, Wojtek Auerbach \\ Andrew J. Murphy ${ }^{\mathrm{e}}$, David M. Valenzuela ${ }^{\mathrm{e}}$, George D. Yancopoulos ${ }^{\mathrm{e}}$, Elizabeth E. Eynon ${ }^{\mathrm{a}, \mathrm{b}, \mathrm{f}}$, Sean Stevens ${ }^{\mathrm{b}, \mathrm{e}, 1}$, \\ Markus G. Manz ${ }^{\mathrm{b}, \mathrm{c}, \mathrm{d}, 2,3}$, and Richard A. Flavell ${ }^{\mathrm{a}, \mathrm{b}, \mathrm{f}, 2,3}$
}

\begin{abstract}
${ }^{a}$ Department of Immunobiology and ${ }^{\mathrm{f} H o w a r d ~ H u g h e s ~ M e d i c a l ~ I n s t i t u t e, ~ Y a l e ~ U n i v e r s i t y ~ S c h o o l ~ o f ~ M e d i c i n e, ~ N e w ~ H a v e n, ~ C T ~ 06520 ; ~}{ }^{\mathrm{b}}$ Bill and Melinda Gates Foundation Grand Challenges in Global Health GC\#4 Consortia, Yale University School of Medicine, New Haven, CT 06520; ' ${ }^{\circ}$ ivision of Hematology, University

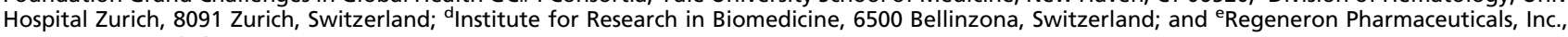
Tarrytown, NY 10591
\end{abstract}

Contributed by Richard A. Flavell, December 29, 2010 (sent for review November 3, 2010)

Hematopoietic stem cells (HSCs) both self-renew and give rise to all blood cells for the lifetime of an individual. Xenogeneic mouse models are broadly used to study human hematopoietic stem and progenitor cell biology in vivo. However, maintenance, differentiation, and function of human hematopoietic cells are suboptimal in these hosts. Thrombopoietin (TPO) has been demonstrated as a crucial cytokine supporting maintenance and self-renewal of HSCs. We generated $\mathrm{RAG2}^{-1-} \gamma_{\mathrm{c}}{ }^{-1-}$ mice in which we replaced the gene encoding mouse TPO by its human homolog. Homozygous humanization of TPO led to increased levels of human engraftment in the bone marrow of the hosts, and multilineage differentiation of hematopoietic cells was improved, with an increased ratio of myelomonocytic verus lymphoid lineages. Moreover, maintenance of human stem and progenitor cells was improved, as demonstrated by serial transplantation. Therefore, RAG2 $^{-1-} \gamma_{\mathrm{c}}{ }^{-1-}$ TPO-humanized mice represent a useful model to study human hematopoiesis in vivo.

$\mathbf{H}$ ematopoietic stem cells (HSCs) are rare cells, defined by two major properties: lifelong self-renewal, and differentiation capacity to all mature hematopoietic lineage cells $(1,2)$. To ensure HSC pool homeostasis, it is believed that upon cell division, HSCs generate on average one functional HSC, whereas the other offspring cell might undergo a highly organized program of differentiation and cellular expansion, during which multiple lineages of committed progenitors and, ultimately, terminally differentiated cells are produced.

Mouse hematopoiesis has been extensively studied during the past decades, leading to the identification and functional characterization of immunophenotypically defined cellular populations, highly enriched in stem and progenitor cells in vivo (2). However, prospective experimental in vivo studies of human lifelong hematopoiesis have been limited by obvious practical and ethical restrictions.

To circumvent this limitation, several substitute, xenogeneic transplantation models for in vivo human hematopoiesis studies have been developed (3). Of these models, transplantation of human hematopoietic cells into immunodeficient mice has been broadly established in experimental hematopoiesis laboratories (3-8). The models most commonly used today rely on the BALB/c Rag $2^{-/-} \gamma_{\mathrm{c}}{ }^{-/-}$or NOD-SCID $\gamma_{\mathrm{c}}{ }^{-\gamma-}$ strains of mice (9-11). Both strains are highly immunodeficient, lacking B, T, and NK cells, and their genetic background is permissive for human hematopoietic engraftment and differentiation. Upon human $\mathrm{CD} 34^{+}$hematopoietic stem and progenitor cell transplantation, most human hematopoietic populations (including B cells, T cells, monocytes, dendritic cells, erythrocytes, and platelets) can develop and are detectable in these models $(7,8,10-12)$. However, in those chimeric animals, there is a bias toward lymphoid development with initially high B-cell counts, myelomonocytic development is relatively minor, and engraftment levels usually start to decline 4-6 mo after transplantation. Moreover, the xenogenic engraftment of human cells into mice requires transplantation of large numbers of cells compared with the numbers that are sufficient for the optimal engraftment of mouse hematopoietic stem and progenitor cells into mice, or human cells into humans, respectively (13). Furthermore, in contrast to mouse HSCs transplanted into mouse recipients (14), human HSCs do not expand, and there is no definitive evidence for lifelong maintenance in the xenogeneic mouse environment (13). Thus, the mouse background provides a suboptimal environment to study the physiology of human HSCs. We therefore hypothesized that this defect might be due to absence or limited cross-reactivity of growth factors required to support the function and maintenance of HSCs $(13,15)$.

Thrombopoietin (TPO) was initially identified as a growth factor that promotes the development of megakaryocytes and platelets (16-22). TPO is constitutively produced by the liver and the kidneys and released into the blood circulation. The receptor for TPO, c-Mpl, is expressed by hematopoietic stem and progenitor cells in the bone marrow. C-Mpl is also expressed on circulating platelets. However, the binding of TPO on platelets does not activate any signaling pathway. Thus, thrombocytes act as a sink or scavengers for TPO and contribute to negative regulation of thrombopoiesis. Subsequently, TPO has been recognized for its important function to support the expansion and selfrenewal of HSCs $(23,24)$. In adult mice, TPO deficiency leads to reduced numbers of HSCs, and the presence of TPO is needed to maintain adult HSCs in quiescence $(25,26)$. Furthermore, TPO is required to support posttransplantation expansion of mouse HSCs, necessary to replenish the hematopoietic compartment of irradiated hosts $(23,26)$. Interestingly, it has been demonstrated that osteoblastic cells involved in forming the HSC "niche" in the bone marrow produce TPO, critical for HSC function and maintenance (25).

Although mouse and human TPO are both-sided cross-reactive to the respective cognate receptors when used at supraphysiological doses in vitro, affinity and biologic activity might differ when the cytokine acts at limiting, physiological doses in context of an in vivo environment, particularly in the microenvironment of the HSC niche in the bone marrow. We thus hypothesized that mouse TPO might not provide an appropriate stimulus to the human c-Mpl receptor in vivo and, therefore, could account for the impaired properties of human HSCs in the mouse environment. To correct this potential defect, we replaced the gene encoding mouse TPO by its human counterpart in Rag2 $2^{-/-} \gamma_{\mathrm{c}}{ }^{-\gamma-}$ mice.

\footnotetext{
Author contributions: A.R., T.W., E.E.E., S.S., M.G.M., and R.A.F. designed research; A.R., T.W., H.T., C.R., W.A., A.J.M., D.M.V., G.D.Y., and S.S. performed research; A.R., T.W., M.G.M., and R.A.F. analyzed data; and A.R. and M.G.M. wrote the paper.

The authors declare no conflict of interest.

'Present address: AnaptysBio, Inc., San Diego, CA 92121

${ }^{2}$ M.G.M. and R.A.F. contributed equally to this work

${ }^{3}$ To whom correspondence may be addressed. E-mail: Markus.Manz@usz.ch or richard. flavell@yale.edu.
}

This article contains supporting information online at www.pnas.org/lookup/suppl/doi:10. 1073/pnas.1019524108/-/DCSupplemental. 


\section{Results}

Thrombopoietin Gene Replacement and Expression Analysis. To replace the gene encoding mouse TPO by its human homolog, we generated a targeting vector by using the VELOCIGENE technology (27). This vector was designed to replace the sequence encompassing the ORF of Tpo, but to maintain the promoter and $5^{\prime}$ UTR of mouse origin (Fig. S1). This targeting construct was electroporated into $F_{1} \mathrm{BALB} / \mathrm{c} \times 129 \mathrm{Rag} 2^{+/-} \gamma_{\mathrm{c}} \mathrm{Y} /-\mathrm{ES}$ cells, and correctly targeted ES cell clones were identified by real-time PCR (27). Chimeras were generated and their progeny were intercrossed to obtain $\mathrm{Rag} 2^{-/-} \gamma_{c}{ }^{-/-}$mice with wild-type Tpo $\left(\mathrm{TPO}^{\mathrm{m} / \mathrm{m}}\right)$, heterozygous $\left(\mathrm{TPO}^{\mathrm{h} / \mathrm{m}}\right)$, or homozygous $\left(\mathrm{TPO}^{\mathrm{h} / \mathrm{h}}\right)$ TPO gene replacement.

To determine whether human $T P O$ is faithfully expressed in these mice, we first extracted total RNA from a variety of organs from a $\mathrm{TPO}^{\mathrm{h} / \mathrm{m}}$ mouse, and we observed a similar pattern of expression for both mouse and human mRNA encoding TPO by RTPCR (Fig. 1 $A$ ). Next, we compared the expression in three tissues or cell types known to express TPO (liver, kidney, and mesenchymal multipotent stromal cells) from $\mathrm{TPO}^{\mathrm{m} / \mathrm{m}}, \mathrm{TPO}^{\mathrm{h} / \mathrm{m}}$, and $\mathrm{TPO}^{\mathrm{h} / \mathrm{h}}$ mice. We detected the expression of mouse Tpo in samples from $\mathrm{TPO}^{\mathrm{m} / \mathrm{m}}$ and $\mathrm{TPO}^{\mathrm{h} / \mathrm{m}}$ mice, whereas human $T P O$ was expressed in $\mathrm{TPO}^{\mathrm{h} / \mathrm{m}}$ and $\mathrm{TPO}^{\mathrm{h} / \mathrm{h}}$ (Fig. $\left.1 B\right)$. We also measured the concentrations of TPO protein in the serum of the targeted mice. Mouse TPO was detected in $\mathrm{TPO}^{\mathrm{m} / \mathrm{m}}$ and $\mathrm{TPO}^{\mathrm{h} / \mathrm{m}}$ animals and human TPO in $\mathrm{TPO}^{\mathrm{h} / \mathrm{m}}$ and $\mathrm{TPO}^{\mathrm{h} / \mathrm{h}}$ (Fig. $1 C$ ). The concentrations measured for human TPO were $\approx 10$-fold lower than mouse TPO. However, this difference is consistent with the respective physiological concentrations reported in healthy human and mouse (Fig. $1 C)$. The expression of human TPO is highly regulated at the posttranscriptional level by mechanisms that involve alternative splicing and restriction of the initiation of translation $(28,29)$. These mechanisms ensure that the serum concentration of TPO is maintained at a low level. Patients carrying mutations leading to dysregulated translation of TPO have increased levels of circulating TPO and develop hereditary thrombocythaemia (29). The posttranscriptional mechanisms of mouse TPO have not been studied in detail. Nevertheless, these observations suggest that the concentrations of human TPO measured in the serum of TPO ${ }^{\mathrm{h} / \mathrm{h}}$
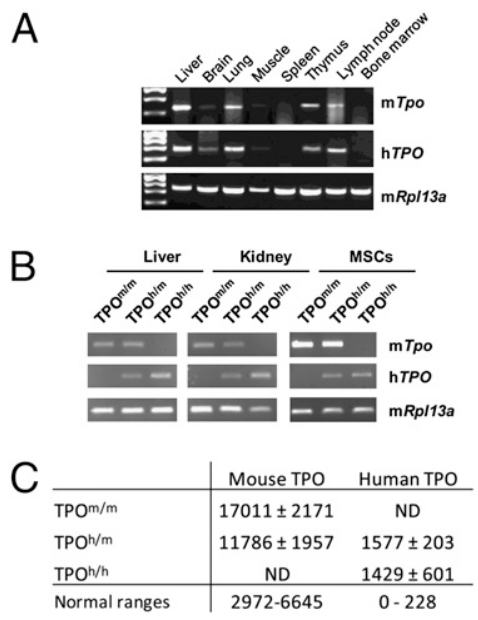

Fig. 1. Faithful tissue-specific expression of human TPO in knock-in mice. $(A)$ RT-PCR analysis of mouse TPO (mTpo) and human TPO (hTPO) expression in different tissues of a Rag2 ${ }^{+/-} \gamma_{\mathrm{c}}{ }^{\mathrm{Y} /-} \mathrm{TPO}^{\mathrm{h} / \mathrm{m}}$ mouse. Mouse Rp/13a was used as housekeeping gene. (B) RT-PCR analysis of $\mathrm{mTpo}$ and $\mathrm{hTPO}$ expression in liver, kidney, and mesenchymal multipotent stromal cells (MSCs) of Rag2 $2^{-1-} \gamma_{\mathrm{c}}{ }^{-1-}$ $\mathrm{TPO}^{\mathrm{m} / \mathrm{m}}, \mathrm{TPO}^{\mathrm{h} / \mathrm{m}}$, and $\mathrm{TPO}^{\mathrm{h} / \mathrm{h}}$ mice. $(C)$ Concentrations of mouse and human TPO proteins measured by ELISA in serum of $\mathrm{TPO}^{\mathrm{m} / \mathrm{m}}, \mathrm{TPO}^{\mathrm{h} / \mathrm{m}}$, and $\mathrm{TPO}^{\mathrm{h} / \mathrm{h}}$ mice (in $\mathrm{pg} / \mathrm{mL}$, mean $\pm \mathrm{SD}, n=7-9$ ). ND, not detected. The normal ranges indicated are from R\&D Systems, Thrombopoietin Quantikine kits. mice reflect physiological human values, which are of importance for normal human hematopoieisis.

Improved Human Engraftment Levels in Bone Marrow of $\mathrm{TPO}^{\mathrm{h} / \mathrm{h}}$ Recipient Mice. We then engrafted $2 \times 1.5$ Gy irradiated newborn $\mathrm{Rag}^{-/-} \gamma_{\mathrm{c}}{ }^{-/-} \mathrm{TPO}^{\mathrm{m} / \mathrm{m}}, \mathrm{TPO}^{\mathrm{h} / \mathrm{m}}$, and $\mathrm{TPO}^{\mathrm{h} / \mathrm{h}}$ mice with human $\mathrm{CD}_{3} 4^{+}$cells purified from cord blood or fetal liver and analyzed engraftment in bone marrow 3-4 mo or 6-7 mo later. Although the total cellularity was comparable in both groups (Fig. S2 $A$ and $B$ ), we observed a significant increase in the percentages (Fig. $2 A$ and $B$ and Fig. S2B) and absolute numbers (Fig. $2 C$ and Fig. S2 $B$ and $C$ ) of human hematopoietic cells $\left(\mathrm{hCD} 45^{+}\right.$) in bone marrow of $\mathrm{TPO}^{\mathrm{h} / \mathrm{h}}$ compared with $\mathrm{TPO}^{\mathrm{m} / \mathrm{m}}$ recipients at both time points. In contrast, we did not observe any improvement in human engraftment in the bone marrow of heterozygous $\mathrm{TPO}^{\mathrm{h} / \mathrm{m}}$ recipients (Fig. S2E), suggesting that complete mouse Tpo deficiency and/or two copies of the human $T P O$ allele are required to support human hematopoiesis.

Interestingly, $\mathrm{TPO}^{\mathrm{h} / \mathrm{h}}$ recipients also displayed a lower engraftment variability, with an at least $80 \%$ human chimerism in $75 \%$ of the mice at $3-4$ mo (Fig. $2 B$ ). The effect of homozygous TPO replacement did not depend on the source of the human $\mathrm{CD}^{+} 4^{+}$cells, because a similar increase in chimerism in $\mathrm{TPO}^{\mathrm{h} / \mathrm{h}}$ hosts was observed with cells derived from cord blood and from fetal liver (Fig. S2D). Finally, although numbers of human cells declined in $\mathrm{TPO}^{\mathrm{m} / \mathrm{m}}$ hosts between the early and later time
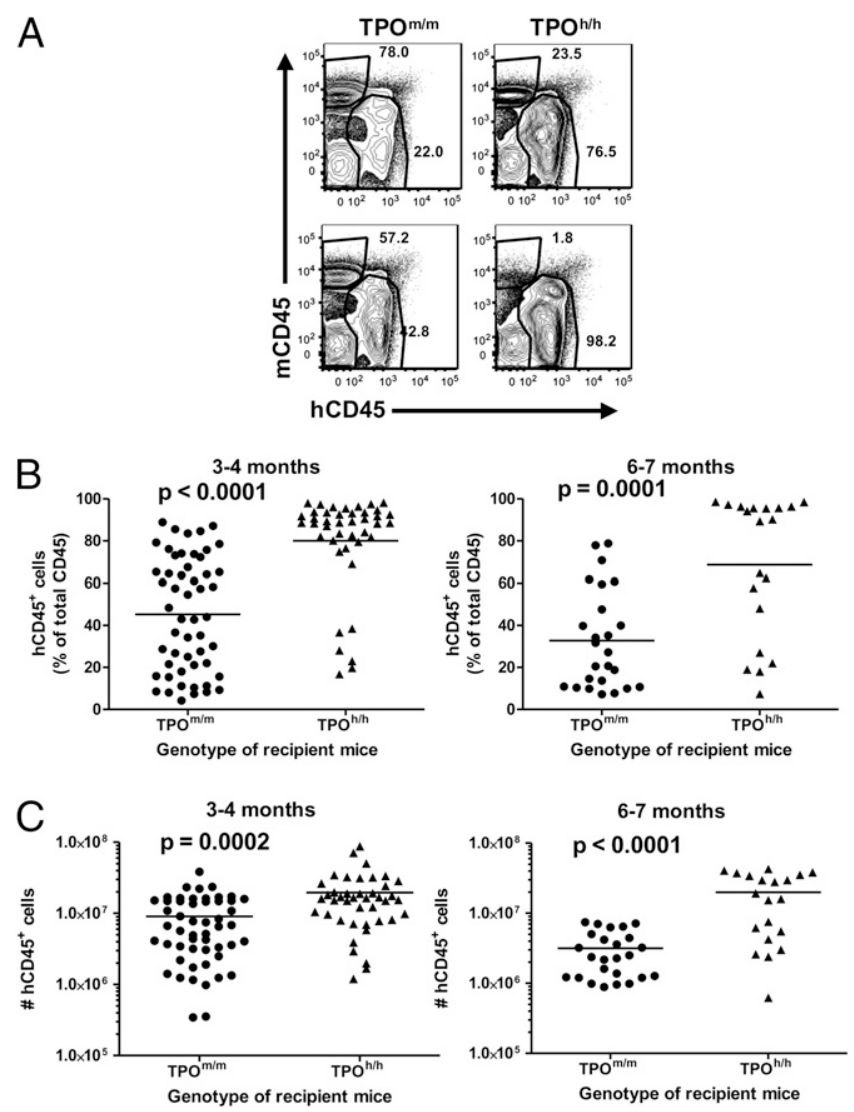

Fig. 2. Improved human engraftment levels in bone marrow of $\mathrm{TPO}^{\mathrm{h} / \mathrm{h}} \mathrm{re}$ cipient mice. $(A)$ Representative FACS analysis of human and mouse CD45 $5^{+}$ cells in bone marrow of $\mathrm{TPO}^{\mathrm{m} / \mathrm{m}}$ and $\mathrm{TPO}^{\mathrm{h} / \mathrm{h}}$ mice 3-4 mo after engraftment. Percentages of mouse and human $\mathrm{CD} 45^{+}$cells among the total CD45 cell populations are indicated. (B) Percentages of human $C D 45^{+}$cells in the bone marrow 3-4 mo (Left; $n=42-53$ ) or 6-7 mo (Right; $n=20-25$ ) after transplantation. Each symbol represents an individual mouse; horizontal bars indicate mean values. $(C)$ Absolute numbers of human $C D 45^{+}$cells in the bone marrow of the same animals as in $B$. 
points, they remained constant in $\mathrm{TPO}^{\mathrm{h} / \mathrm{h}}$ animals (Fig. $2 C$ and Fig. S2C). These results are consistent with the previously described functions of TPO in the mouse. First, TPO favors the expansion of HSCs after transplantation into irradiated recipient mice, leading to increased engraftment levels $(23,26)$; second, it favors the maintenance of adult HSCs, leading to sustained hematopoiesis throughout adult life (26).

Effect of TPO Humanization on Mouse and Human Platelets. Because TPO is well-known for its nonredundant function on thrombopoiesis (22), we determined whether TPO humanization affected platelet development. Humanization of both alleles of the TPO gene led to an approximately twofold reduction in mouse blood platelet counts of nonengrafted $\operatorname{Rag} 2^{-/-} \gamma_{\mathrm{c}}{ }^{-1-}$ mice (Fig. 3A) After engraftment with human cells, we found that the counts of mouse platelets in $\mathrm{TPO}^{\mathrm{h} / \mathrm{h}}$ mice were further decreased, to $<25 \%$ of normal values (Fig. 3D). The ratio of human to mouse platelets (Fig. $3 B$ and $C$ ), as well as the absolute counts of human platelets (Fig. $3 E$ ), tended to be higher in $\mathrm{TPO}^{\mathrm{h} / \mathrm{h}}$ mice than in $\mathrm{TPO}^{\mathrm{m} / \mathrm{m}}$, but none of these differences reached statistical significance. Furthermore, the percentage of bone marrow megakaryocytes $\left(\mathrm{CD} 41 \mathrm{a}^{+}\right.$cells) among human cells was comparable in both strains (Fig. $3 F$ ). The mouse population of megakaryocytes $\left(\mathrm{CD} 42 \mathrm{~b}^{+}\right)$was also unaffected by the gene replacement in both nonengrafted and engrafted mice. These results demonstrate that levels or biologic activity of human TPO reached by our knock-in strategy are not sufficient to fully replace mouse TPO function and furthermore suggest that human TPO on its own is not sufficient to support human thrombopoiesis in the mouse environment.

Multilineage Hematopoiesis in TPO-Humanized Mice. Next, we determined whether human TPO could favor multilineage differentiation of human hematopoietic stem and progenitor cells in vivo. As previously reported $(10,11)$, the engrafted human cells predominantly gave rise to $\mathrm{B}$ cells $\left(\mathrm{CD} 19^{+}\right)$in wild-type $\mathrm{Rag} 2^{-/}$ $\gamma_{c}{ }^{-/-}$hosts $(61.51 \pm 4.71 \%$ of the human cells in the spleen, mean \pm SEM, $n=32$ ) with, compared with hematopoiesis in humans, only a small fraction of myeloid cells. When we compared $\mathrm{TPO}^{\mathrm{m} / \mathrm{m}}$ and $\mathrm{TPO}^{\mathrm{h} / \mathrm{h}}$ recipients, we observed a significant increase in the frequency and absolute numbers of $\mathrm{CD} 3^{+}$myeloid cells in the bone marrow of TPO ${ }^{\mathrm{h} / \mathrm{h}}$ mice (Fig. $4 A$ and $B$ and
Fig. S3A). This increase was mostly due to granulocytes $\left(\mathrm{CD} 33^{+}\right.$ CD $66^{\text {hi }}$ SSC $^{\text {hi }}$ cells), whereas the fraction of monocytes $\left(\mathrm{CD} 33^{\text {hi }} \mathrm{C}\right.$ D $66{ }^{\text {lo }} \mathrm{CD} 14^{+}$) was almost similar in both strains (Fig. $4 A, C$, and $D$ and Fig. S3 $B$ and $C$ ). The percentage of myeloid cells (both granulocytes and monocytes) was also significantly increased in the peripheral blood of TPO ${ }^{\mathrm{h} / \mathrm{h}}$ animals (Fig. S $\left.D-F\right)$. Accordingly, we found that the population of bone marrow progenitors phenotypically described as highly enriched in granulocyte-monocyte progenitors (30) (GMP; $\mathrm{Lin}^{-} \mathrm{CD} 34^{+} \mathrm{CD} 38^{+} \mathrm{CD} 123^{\mathrm{lo}} \mathrm{CD} 45 \mathrm{RA}{ }^{+}$) was increased relative to the population of common myeloid progenitors (CMP; Lin $^{-} \mathrm{CD} 34^{+} \mathrm{CD} 38^{+} \mathrm{CD} 123^{\mathrm{lo}} \mathrm{CD} 45 \mathrm{RA}^{-}$) (Fig. $\left.4 E\right)$.

Effect of TPO Humanization on Mouse and Human Hematopoietic Stem and Progenitor Cells. We next analyzed the effect of human TPO on the number and function of cellular populations enriched for HSCs and progenitor cells. Genetic deletion of TPO leads to a reduction of HSCs in adult mice (26). To determine whether TPO humanization affects the mouse population immunophenotypically defined as containing mouse HSCs, we compared the percentages of mouse lineage-negative $\mathrm{Sca}^{+}{ }^{+} \mathrm{c}-\mathrm{Kit}^{+}$ cells in bone marrow of nonengrafted $\mathrm{TPO}^{\mathrm{m} / \mathrm{m}}, \mathrm{TPO}^{\mathrm{h} / \mathrm{m}}$, and $\mathrm{TPO}^{\mathrm{h} / \mathrm{h}}$ adult mice. We observed a significant reduction in the percentage of these cells in both $\mathrm{TPO}^{\mathrm{h} / \mathrm{m}}$ and $\mathrm{TPO}^{\mathrm{h} / \mathrm{h}}$ mice compared with $\mathrm{TPO}^{\mathrm{m} / \mathrm{m}}$ (Fig. $5 A$ and $B$ ), suggesting that human TPO is either not fully cross-reactive on the mouse receptor or is not available in sufficient amounts to support the mouse cells in this knock-in setting.

We then characterized the human $\mathrm{CD} 34^{+}$populations in the bone marrow of engrafted $\mathrm{TPO}^{\mathrm{m} / \mathrm{m}}$ and $\mathrm{TPO}^{\mathrm{h} / \mathrm{h}}$ hosts. Human HSCs with long-term repopulating potential are contained in the $\mathrm{Lin}^{-} \mathrm{CD} 34^{+} \mathrm{CD} 38^{-}$cell fraction $(5,31-33)$. The percentage of $\mathrm{CD} 34^{+}$cells among the human $\mathrm{CD} 45^{+}$population was slightly increased in $\mathrm{TPO}^{\mathrm{h} / \mathrm{h}}$ mice $(12.39 \pm 0.79 \%$ vs. $10.00 \pm 0.81 \%$, mean \pm SEM, $n=43-53, P=0.037)$. We also observed a small $(1.5$-fold $)$ but statistically significant increase in the percentage of CD38 cells within the CD $34^{+}$population in $\mathrm{TPO}^{\mathrm{h} / \mathrm{h}}$ compared with $\mathrm{TPO}^{\mathrm{m} / \mathrm{m}}$ recipients (Fig. $5 C$ and $D$ ). Overall, it resulted in a significant increase $\left(\approx 2.8\right.$-fold) of absolute numbers of $\mathrm{CD} 34^{+}$ CD $38^{-}$cells in TPO-humanized mice (Fig. $5 E$ ). Next, we characterized the $\mathrm{Lin}^{-} \mathrm{CD} 34^{+} \mathrm{CD} 38^{-}$population based on the expression of CD90 and CD45RA. The CD90 ${ }^{+} \mathrm{CD} 45 \mathrm{RA}^{-}$fraction
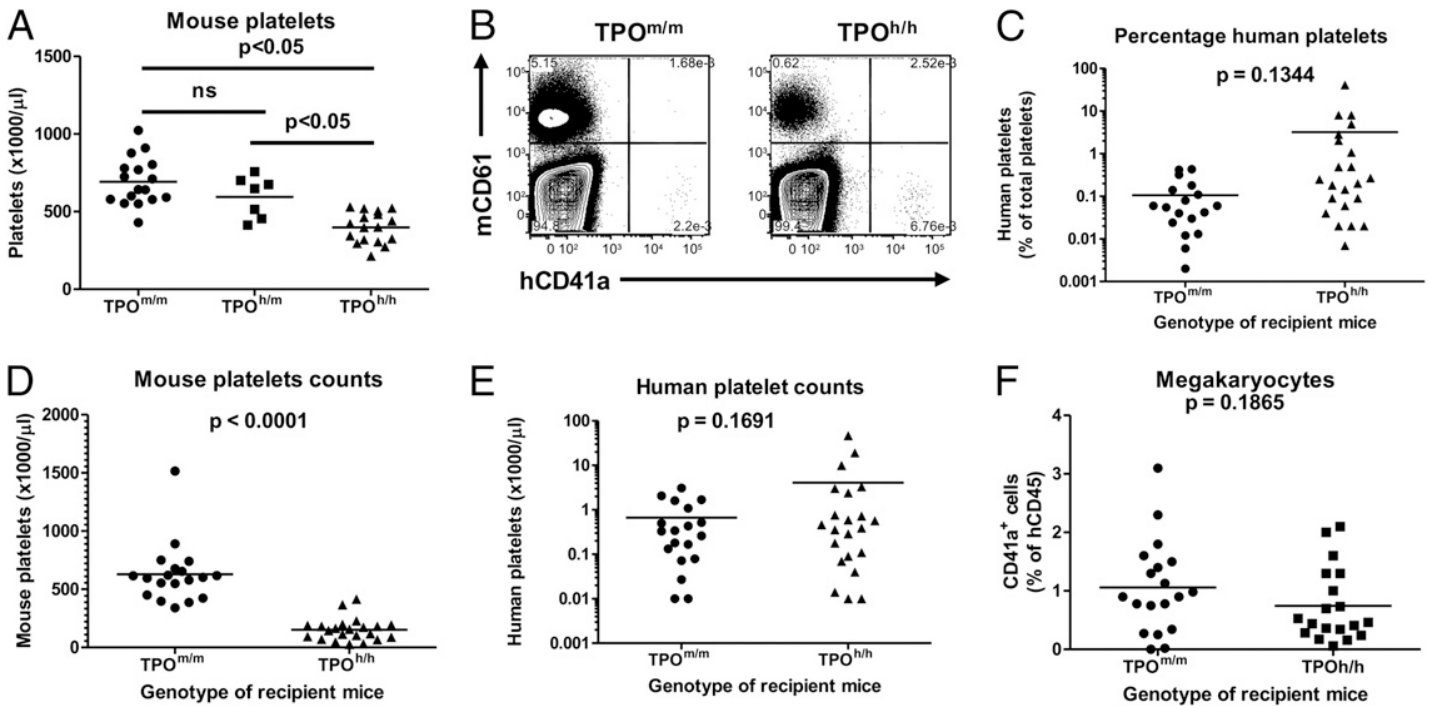

Fig. 3. Effect of TPO humanization on mouse and human platelets. $(A)$ Platelet counts in the blood of adult nonengrafted mice. $P<0.0001$ (one-way ANOVA, $n=7-17 ; P$ values calculated with the Tukey post hoc test). ( $B$ ) Representative FACS analysis of mouse (mCD61 ${ }^{+}$) and human (hCD41 $\left.{ }^{+}\right)$platelets in the blood of $\mathrm{TPO}^{\mathrm{m} / \mathrm{m}}$ and $\mathrm{TPO}^{\mathrm{h} / \mathrm{h}}$ mice 3-4 mo after engraftment. The numbers indicate percentages among total events. (C) Human platelet chimerism, determined by FACS, in TPO ${ }^{\mathrm{m} / \mathrm{m}}$ and TPO ${ }^{\mathrm{h} / \mathrm{h}}$ mice $(n=19-22)$. Only mice with a percentage of human CD45 cells in the blood $>5 \%$ were included in this analysis. $(D$ and $E)$ Counts of mouse $\left(\mathrm{mCD} 1^{+} ; D\right)$ and human $\left(\mathrm{hCD} 41 \mathrm{a}^{+} ; E\right)$ platelets in the blood. $(F)$ Human megakoryocyte percentages $\left(C D 41 \mathrm{a}^{+}\right)$among human CD45 $5^{+}$cells in the bone marrow. 
A
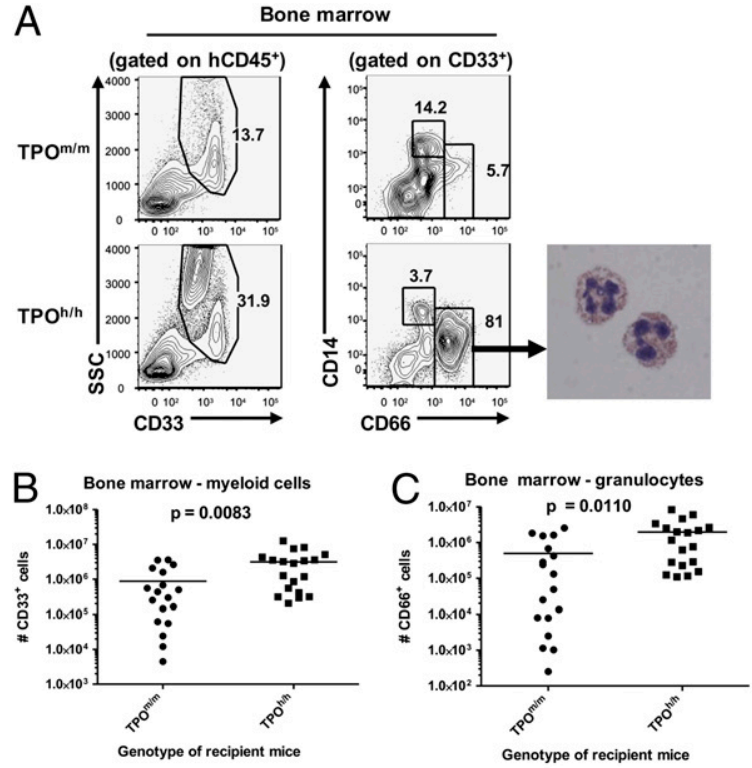

$\mathrm{D}$

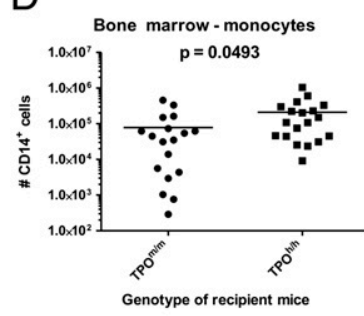

$E$

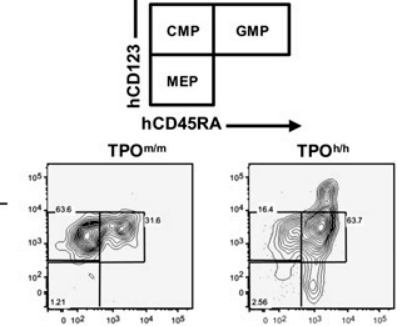

Fig. 4. Improved multilineage hematopoiesis in human TPO knock-in mice. (A) Representative FACS analysis of human myeloid cell populations in bone marrow. (Right) DiffQuick staining of hCD $45^{+} S S C^{\text {hi }} \mathrm{CD} 33^{+} \mathrm{CD} 66^{\text {hi }}$ cells purified from the bone marrow of $\mathrm{TPO}^{\mathrm{h} / \mathrm{h}}$ recipients. $(B-D)$ Absolute numbers of human myeloid cell populations in bone marrow $(n=19)$. (B) Total myeloid populations (CD33 ${ }^{+}$cells). (C) Granulocytes (CD33 $\left.{ }^{+} \mathrm{CD}_{66}{ }^{\mathrm{hi}}\right)$. (D) Monocytes $\left(\mathrm{CD} 33^{+} \mathrm{CD} 66{ }^{\mathrm{lo}} \mathrm{CD} 14^{+}\right)$. (E) FACS analysis of the myeloid progenitors population, based on the expression of CD123 and CD45RA, among CD $34^{+}$cells isolated from the bone marrow and gated on the $\mathrm{Lin}^{-} \mathrm{CD} 38^{+}$population. The plots shown are representative of 3-5 mice per group.

has been described as highly enriched in long-term stem cells that are functionally able to establish multipotent hematopoiesis in vivo and to generate successful secondary transplants (34). We measured a significantly higher proportion of this $\mathrm{CD} 90^{+}$ $\mathrm{CD}_{45 \mathrm{RA}^{-}}$cell population in the $\mathrm{Lin}^{-} \mathrm{CD} 34^{+} \mathrm{CD} 38^{-}$fraction from $\mathrm{TPO}^{\mathrm{h} / \mathrm{h}}$ compared with $\mathrm{TPO}^{\mathrm{m} / \mathrm{m}}$ (Fig. $5 F$ and $G$ ). Thus, based on cell surface immunophenotype, human TPO favors populations of cells known to be highly enriched for HSCs.

To address the functional properties of this cell population, we purified human $\mathrm{CD} 34^{+}$cells from the bone marrow of $\mathrm{TPO}^{\mathrm{m} / \mathrm{m}}$ and $\mathrm{TPO}^{\mathrm{h} / \mathrm{h}}$ mice and assessed them in methylcellulose colony formation assays in vitro. The formation of CFU-GEMM, CFU$\mathrm{G}$, and CFU-M was modestly higher in human $\mathrm{CD}^{+} 4^{+}$cell samples isolated from $\mathrm{TPO}^{\mathrm{h} / \mathrm{h}}$ compared with $\mathrm{TPO}^{\mathrm{m} / \mathrm{m}}$ mice (Fig. S4).

The capacity of HSC to maintain and/or self-renew in vivo is best demonstrated functionally by successful secondary transplants. "Scid repopulating cells" (SRCs) that serially engraft in mice represent the surrogate experimental "gold standard" for human HSC function (35). We therefore purified human CD34 ${ }^{+}$ cells from bone marrow of $\mathrm{TPO}^{\mathrm{m} / \mathrm{m}}$ and $\mathrm{TPO}^{\mathrm{h} / \mathrm{h}}$ primary recipients and transplanted them in equally low numbers $\left(100,000 \mathrm{CD} 34^{+}\right.$ cells per animal) into Rag2 $2^{-1-} \gamma_{c}^{-/-}$newborn mice. Bone marrow of secondary recipients was analyzed 8 wk later (Fig. $5 H$ ). Human

$\mathrm{CD} 4^{+}$cells isolated from $\mathrm{TPO}^{\mathrm{m} / \mathrm{m}}$ primary recipients had a very low capacity to serially engraft, because human $\mathrm{CD} 45^{+}$cells were detected in only 2 of 11 secondary recipients. By contrast, human $\mathrm{CD} 45^{+}$cells were present in the bone marrow of 15 of 19 mice engrafted with CD34 ${ }^{+}$cells isolated from $\mathrm{TPO}^{\mathrm{h} / \mathrm{h}}$ primary recipients $(P=0.0012)$. Because the genotype of the secondary recipient mice was the same for both groups $\left(\mathrm{TPO}^{\mathrm{m} / \mathrm{m}}\right)$, this result indicates that the presence of human TPO in the primary recipient favored the maintenance of human cells with enhanced selfrenewal capacity.

Taken together, these results demonstrate that homozygous TPO-humanized mice represent a better environment to maintain self-renewal capacity and multilineage differentiation potential of human hematopoietic stem and/or progenitor cells.

\section{Discussion}

Significant progress has been achieved in the development of mice that sustain differentiation and function of the human hematolymphopoietic system since the publication of the first models more than two decades ago $(3,4,7,8)$. However, several limitations remain, including $(i)$ human cell engraftment is only transient, not lasting for the life of recipient mice (which could be due to the inherent low frequency of long-term HSC in the human $\mathrm{CD} 4^{+}$cell population, as well as to the suboptimal environment provided by the mouse host), (ii) the unphysiological bias toward the lymphoid lineage as well as poor differentiation of myeloid cells, and (iii) the variability in the engraftment levels between different individual animals, even when groups of mice are transplanted with cells from a single human donor. These limitations might be due to nonphysiologic location of human cells, residual xenoreactivity of the immunodeficient host, different composition of hematolymphoid cells in mouse and human species, and/or due to lack or insufficient mouse-to-human crossreactivity of hematopoiesis supporting factors, leading to preferential mouse cell support $(13,15)$. Here, we describe a unique strain of recipient mice in which we humanized the gene encoding thrombopoietin, a cytokine with important functions in the maintenance and self-renewal of HSCs.

Upon engraftment of these mice with human $\mathrm{CD} 34^{+}$, we observed significant improvement in all three limitations listed above: bone marrow chimerism was higher and was maintained for at least $6 \mathrm{mo}$; multilineage, particularly myeloid lineage differentiation was enhanced; and variability in engraftment levels was reduced.

The concentrations of human TPO in the knock-in mice was $\approx 10$-fold lower than the concentrations of mouse TPO, reflecting the physiological values in each species. A priori, it could be possible that the observed effect of the gene replacement is the result of a knock down of TPO expression leading to decreased mouse hematopoiesis and a concomitant competitive advantage for human cells, rather than a specific positive effect of human TPO. However, the analysis of heterozygous $\mathrm{TPO}^{\mathrm{h} / \mathrm{m}}$ suggests that this hypothesis is unlikely, although such a competitive advantage probably contributes to the improved human cell engraftment. Specifically, the heterozygous replacement of the Tpo gene in $\mathrm{TPO}^{\mathrm{h} / \mathrm{m}}$ mice leads to a defect in mouse HSCs that is not further exacerbated by the elimination of the second copy of the mouse gene in $\mathrm{TPO}^{\mathrm{h} / \mathrm{h}}$ mice (Fig. $5 A$ and $B$ ). If the defect in mouse HSC was the only factor responsible for enhanced human hematopoiesis, we should observe the same increase in human hematopoiesis in $\mathrm{TPO}^{\mathrm{h} / \mathrm{m}}$ as that observed in $\mathrm{TPO}^{\mathrm{h} / \mathrm{h}}$ because both have the same degree of reduction of mouse HSCs. However, we did not observe any enhanced engraftment in $\mathrm{TPO}^{\mathrm{h} / \mathrm{m}}$ compared with $\mathrm{TPO}^{\mathrm{m} / \mathrm{m}}$ recipients (Fig. S2E). Therefore, superior human hematopoiesis is achieved in $\mathrm{TPO}^{\mathrm{h} / \mathrm{h}}$ mice where $(i)$ mouse HSCs are defective, potentially increasing the space available for human cells and (ii) two copies of the human TPO gene are present to support human cell development. Both effects likely contribute to the increased human engraftment; moreover, these results argue that both genes are haploinsufficient. 

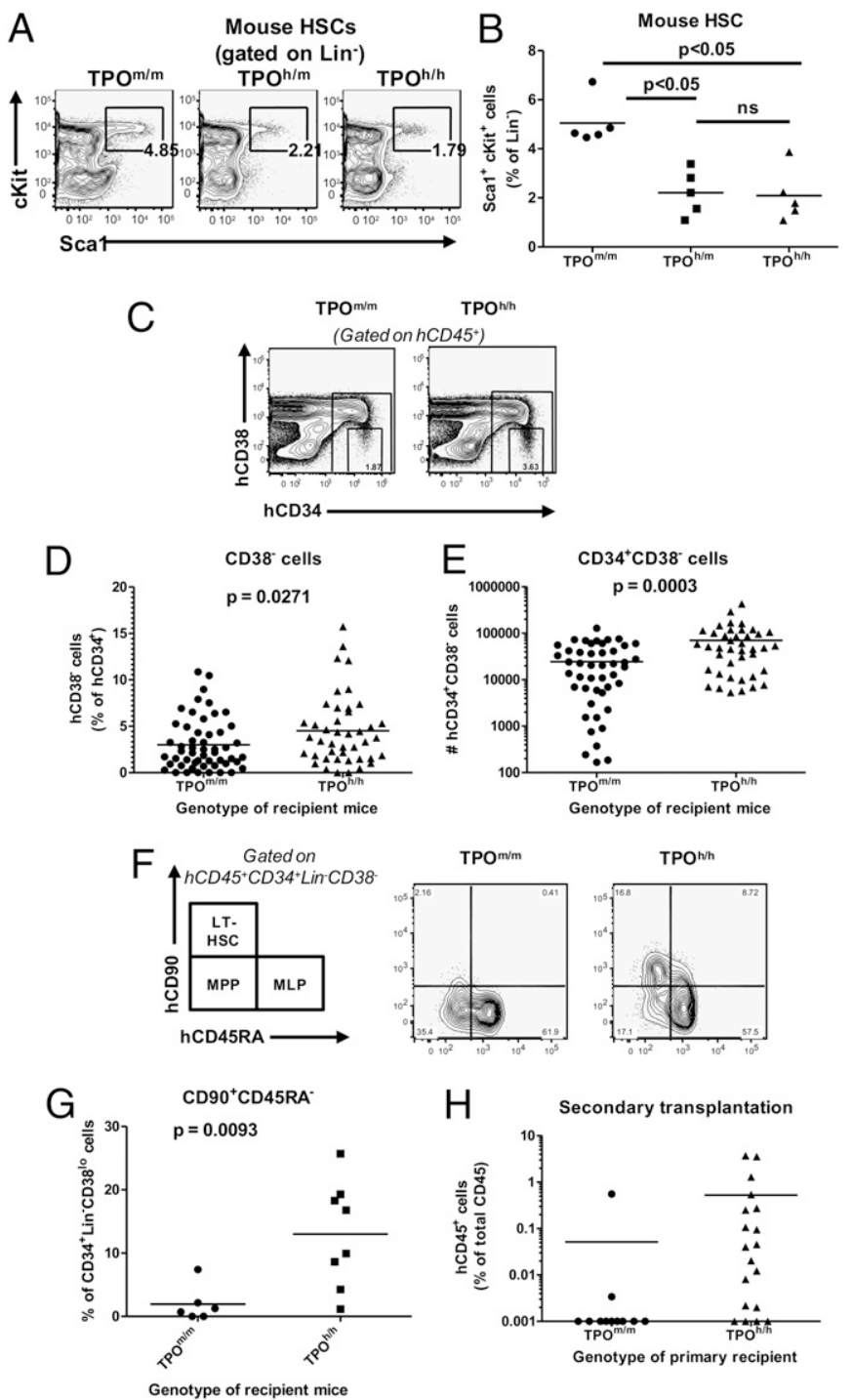

Fig. 5. Decreased mouse $\mathrm{lin}^{-} \mathrm{C}-\mathrm{Kit}^{+} \mathrm{Sca} 1^{+}$cells and increased number and self-renewal potential of human stem and progenitor cells in bone marrow of human TPO knock-in mice. $(A)$ Representative FACS analysis of mouse $\mathrm{Lin}^{-} \mathrm{Sca}{ }^{+}{ }^{+} \mathrm{C}-\mathrm{Kit}^{+}$stem and progenitor cells in the bone marrow of nonengrafted mice. Numbers indicate the percentage of $\mathrm{Sca}^{+}{ }^{+} \mathrm{C}-\mathrm{Kit}^{+}$ cells among the $\mathrm{Lin}^{-}$population. $(B)$ Quantitative analysis of the results presented in $A$. $P=0.0006$ (one-way ANOVA; $P$ values calculated with the Tukey post hoc test; $n=5$ per genotype; representative of two in dependent experiments). (C) Representative FACS analysis of human $\mathrm{CD} 34^{+} \mathrm{CD} 38^{-}$cells in the bone marrow. The numbers indicate the percentage of $C D 38^{-}$cells among the human $C D 45^{+} C D 34^{+}$cells. (D) Quantitative analysis of the percentages of $\mathrm{CD}^{-} 8^{-}$cells in the human $\mathrm{CD} 45^{+} \mathrm{CD} 34^{+}$population $(n=43-53)$. ( $(E)$ Absolute numbers of human $\mathrm{CD} 34^{+} \mathrm{CD} 38^{-}$cells in the bone marrow of the same mice as in $D$. $(F)$ Representative FACS analysis of the hematopoietic stem and progenitor cells, based on the expression of CD90 and CD45RA, among CD34 ${ }^{+}$cells isolated from the bone marrow and gated on the $\mathrm{Lin}^{-} \mathrm{CD}_{3} 8^{-}$population. LT-HSC, long-term hematopoietic stem cells; MPP, multipotent progenitors; MLP, multilymphoid progenitors. $(G)$ Quantitative analysis of the percentages of $\mathrm{Lin}^{-} \mathrm{CD} 34^{+} \mathrm{CD} 38^{-} \mathrm{CD} 90^{+} \mathrm{CD} 45 \mathrm{RA}^{-}$cells, as identified in $F$. $n=6-8$, from two experiments with 4- to 5-mo-old mice. $(H)$ Human $\mathrm{CD} 45^{+} \mathrm{CD}_{3} 4^{+}$cells were purified from Rag2 ${ }^{-1-} \gamma_{\mathrm{c}}{ }^{-1-} \mathrm{TPO}^{\mathrm{m} / \mathrm{m}}$ and $\mathrm{TPO}^{\mathrm{h} / \mathrm{h}}$ primary recipient mice, transplanted into newborn $\operatorname{Rag}^{-1-} \gamma_{\mathrm{c}}{ }^{-1-}$ mice $\left(100,000\right.$ cells per mouse), and human $C D 45^{+}$chimerism was determined in secondary recipients $8 \mathrm{wk}$ later. The results are pooled from two independent experiments ( $n=7-12$ primary recipients, $n=11-19 \mathrm{sec}$ ondary recipients).
Besides its role in the regulation of the functional properties of HSCs, TPO is a critical cytokine required for platelet development. Replacement of the TPO-encoding gene leads to a significant decrease in mouse platelets. However, the humanization of TPO did not significantly promote human thrombopoiesis. This result suggests that additional defects exist that prevent adequate development of the human platelet formation. In fact, we detected only a very small fraction of the $\mathrm{Lin}^{-} \mathrm{CD} 34^{+} \mathrm{CD} 38^{+} \mathrm{CD}^{-} \mathrm{RA}^{-} \mathrm{CD}^{-} 3^{-}$(Fig. $4 H$ ), a population phenotypically described as highly enriched in megakarycyte/ erythrocyte progenitors (MEPs) (30).

A major difference between the mouse and human immune systems is the fraction of granulocytes present in the blood (36, 37). Lymphocytes are preponderant in mouse blood, whereas human blood is rich in granulocytes, a difference unclear in its significance. Interestingly, the presence of human TPO improved differentiation of human granulocytes (Fig. 4). Thus, the presence of human TPO in recipient mice favors a balance between granulocytes and lymphocytes that better reflects the human physiological condition, a finding possibly due to better maintenance and/or differentiation of human myeloid progenitor cells.

More importantly, we show that TPO humanization favors the maintenance of a human $\mathrm{CD} 34^{+}$population that can repopulate human hematopoiesis in a secondary recipient (Fig. 5). Hence, the $\mathrm{Rag} 2^{-/-} \gamma_{\mathrm{c}}{ }^{-1-} \mathrm{TPO}^{\mathrm{h} / \mathrm{h}}$ mouse represents a unique model to study various aspects of human stem and progenitor cell function in vivo.

Despite the clear improvement in HSC-like cell populations, as well as a better balance between the myeloid and lymphoid lineages, we did not observe any significant effect of TPO humanization on the overall engraftment levels in peripheral lymphoid tissues or in the percentages of B and T cells (Fig. S5). This result could be explained by different factors. (i) Although the recipient mice are sublethally irradiated before transplantation, a large population of radiation-resistant mouse myeloid cells is still present. Among those cells, macrophages are able to phagocyte human cells and limit the overall engraftment levels in the periphery (38-42). (ii) Human cells may require additional factors to favor their terminal differentiation, egress from the bone marrow, and/or their survival in the periphery. (iii) Finally, although secondary lymphoid organs are formed in humanized mice, their structure is not optimal compared with human tissues $(10,13)$. This partially defective structure might represent a limit to the number of human cells that can survive in these organs. Thus, additional gene replacements will be necessary to further improve the mouse recipients.

The two most widely used mouse models as recipients for human hematopoietic cells are either the BALB/c Rag2 $2^{-/-} \gamma_{\mathrm{c}}{ }^{-/-}$ or the NOD-SCID $\gamma_{c}^{-1-}$ strains. Our approach required the ability to serially target ES cells to efficiently introduce genetic modifications into the mouse genome. Therefore, we chose to use the heterozygote BALB/c $\times 129$ genetic background, which could be reproducibly and serially targeted by homologous recombination and retain viability and pluripotency. ES cells derived from pure $\mathrm{BALB} / \mathrm{c}$ and NOD genetic backgrounds have become available recently, but serial targeting by homologous recombination has yet to be shown.

With both BALB/c and NOD pure backgrounds, the interpretation of the engraftment results are complicated by the high variability between individual recipients. Although BALB/c and 129 alleles segregate randomly in our model, it does not seem to drastically increase the variability compared with the results reported with pure genetic backgrounds $(10,11,43)$. Indeed, despite this increased genetic variability, $\mathrm{TPO}^{\mathrm{h} / \mathrm{h}}$ recipients present more consistent levels of human chimerism in the bone marrow than other models.

Several studies point to a superior capacity of NOD-SCID $\gamma_{c}{ }^{-/-}$ hosts to support human hematopoiesis compared with BALB/c $\operatorname{Rag} 2^{-/-} \gamma_{\mathrm{c}}{ }^{-/}$. A recent report (43), in which the authors performed a comparison of different strains of recipient mice, shows 
that it is particularly true for secondary lymphoid tissues. However, the human chimerism in the bone marrow and thymus is comparable in NOD-SCID $\gamma_{\mathrm{c}}{ }^{-/}$and BALB/c Rag2 ${ }^{-/-} \gamma_{\mathrm{c}}{ }^{-/-}$. Therefore, although we did not perform a direct side-by-side comparison, these observations suggest that the $\mathrm{TPO}^{\mathrm{h} / \mathrm{h}}$ mice represent an improvement relative to both BALB/c Rag2 ${ }^{-/} \gamma_{\mathrm{c}}{ }^{-/-}$ and NOD-SCID $\gamma_{\mathrm{c}}{ }^{-1-}$ to study the bone marrow stages of human hematopoiesis. Furthermore, the serial stepwise humanization of additional genes, permitted by the use of BALB/c $\times 129 \mathrm{ES}$ cells, should further improve different aspects of human hematopoiesis in our model in the near future.

In conclusion, with human TPO knockin mice, we provide a unique model that can be useful to study in vivo physiology of human hematopoiesis in general and human hematopoietic stem and progenitor cells in particular. Moreover, we postulate that these mice might be valuable to sustain in vivo human hematopoietic malignancies that originate from early hematopoietic cells, such as myeloid leukemias and myeloproliferative neoplasias. More generally, we show that gene replacement is a pow-

1. Kondo M, et al. (2003) Biology of hematopoietic stem cells and progenitors: Implications for clinical application. Annu Rev Immunol 21:759-806.

2. Chao MP, Seita J, Weissman IL (2008) Establishment of a normal hematopoietic and leukemia stem cell hierarchy. Cold Spring Harb Symp Quant Biol 73:439-449.

3. McCune JM, et al. (1988) The SCID-hu mouse: Murine model for the analysis of human hematolymphoid differentiation and function. Science 241:1632-1639.

4. Namikawa R, Kaneshima H, Lieberman M, Weissman IL, McCune JM (1988) Infection of the SCID-hu mouse by HIV-1. Science 242:1684-1686.

5. Baum CM, Weissman IL, Tsukamoto AS, Buckle AM, Peault B (1992) Isolation of a candidate human hematopoietic stem-cell population. Proc Natl Acad Sci USA 89 2804-2808.

6. Dick JE, Lapidot T (2005) Biology of normal and acute myeloid leukemia stem cells. Int J Hematol 82:389-396.

7. Shultz LD, Ishikawa F, Greiner DL (2007) Humanized mice in translational biomedical research. Nat Rev Immunol 7:118-130.

8. Legrand N, Weijer K, Spits H (2006) Experimental models to study development and function of the human immune system in vivo. J Immunol 176:2053-2058.

9. Ito $\mathrm{M}$, et al. (2002) NOD/SCID/gamma(c)(null) mouse: An excellent recipient mouse model for engraftment of human cells. Blood 100:3175-3182.

10. Traggiai E, et al. (2004) Development of a human adaptive immune system in cord blood cell-transplanted mice. Science 304:104-107.

11. Ishikawa F, et al. (2005) Development of functional human blood and immune systems in NOD/SCID/IL2 receptor gamma chain(null) mice. Blood 106:1565-1573.

12. Gimeno R, et al. (2004) Monitoring the effect of gene silencing by RNA interference in human $\mathrm{CD} 34+$ cells injected into newborn RAG2-/- gammac-/- mice: Functional inactivation of p53 in developing T cells. Blood 104:3886-3893.

13. Manz MG (2007) Human-hemato-lymphoid-system mice: Opportunities and challenges. Immunity 26:537-541.

14. Allsopp RC, Cheshier S, Weissman IL (2001) Telomere shortening accompanies increased cell cycle activity during serial transplantation of hematopoietic stem cells. J Exp Med 193:917-924.

15. Legrand N, et al. (2009) Humanized mice for modeling human infectious disease: Challenges, progress, and outlook. Cell Host Microbe 6:5-9.

16. Wendling F, et al. (1994) CMpl ligand is a humoral regulator of megakaryocytopoiesis. Nature 369:571-574.

17. Kaushansky K, et al. (1994) Promotion of megakaryocyte progenitor expansion and differentiation by the c-Mpl ligand thrombopoietin. Nature 369:568-571.

18. Lok S, et al. (1994) Cloning and expression of murine thrombopoietin CDNA and stimulation of platelet production in vivo. Nature 369:565-568.

19. de Sauvage FJ, et al. (1994) Stimulation of megakaryocytopoiesis and thrombopoiesis by the c-Mpl ligand. Nature 369:533-538.

20. Bartley TD, et al. (1994) Identification and cloning of a megakaryocyte growth and development factor that is a ligand for the cytokine receptor Mpl. Cell 77:1117-1124.

21. Kaushansky K (1998) Thrombopoietin. N Engl J Med 339:746-754.

22. Kaushansky K (2008) Historical review: Megakaryopoiesis and thrombopoiesis. Blood 111:981-986.

23. Fox N, Priestley G, Papayannopoulou T, Kaushansky K (2002) Thrombopoietin expands hematopoietic stem cells after transplantation. J Clin Invest 110:389-394.

24. Kirito K, Fox N, Kaushansky K (2003) Thrombopoietin stimulates Hoxb4 expression: An explanation for the favorable effects of TPO on hematopoietic stem cells. Blood 102:3172-3178. erful strategy, which holds great promise to bring further progress to the field of humanized mice.

\section{Experimental Procedures}

The human TPO knock-in mice were generated by using the VELOCIGENE (27) and VELOCIMOUSE (44) technologies, as described in the SI Experimental Procedures.

Recipient mice were engrafted with human hematopoietic progenitors as described (10). The mice were killed, and the engraftment of human hematopoietic cells was analyzed 3-4 or 6-7 mo later. All these procedures are detailed in SI Experimental Procedures.

ACKNOWLEDGMENTS. We thank J. Alderman for organizational support A. M. Franco, P. Ranney, and R. Webber for human cell isolation and mouse colony management; G. Lyon, L. Wan, S. Lin, and P. Ziegler for assistance with materials and protocols; D. Krause for helpful discussion; Regeneron's Velocigene team for excellent technical contributions; and F. Manzo for manuscript submission. This work was supported by grants from the Bill and Melinda Gates Foundation through the Grand Challenges in Global Health Initiative and from the Juvenile Diabetes Research Foundation. A.R. was supported by a D. Collen Fellowship of the Belgian American Educational Foundation. R.A.F. is an Investigator of the Howard Hughes Medical Institute.

25. Yoshihara $\mathrm{H}$, et al. (2007) Thrombopoietin/MPL signaling regulates hematopoietic stem cell quiescence and interaction with the osteoblastic niche. Cell Stem Cell 1: 685-697.

26. Qian $\mathrm{H}$, et al. (2007) Critical role of thrombopoietin in maintaining adult quiescent hematopoietic stem cells. Cell Stem Cell 1:671-684.

27. Valenzuela DM, et al. (2003) High-throughput engineering of the mouse genome coupled with high-resolution expression analysis. Nat Biotechnol 21:652-659.

28. Ghilardi N, Wiestner A, Skoda RC (1998) Thrombopoietin production is inhibited by a translational mechanism. Blood 92:4023-4030.

29. Wiestner A, Schlemper RJ, van der Maas AP, Skoda RC (1998) An activating splice donor mutation in the thrombopoietin gene causes hereditary thrombocythaemia. Nat Genet 18:49-52.

30. Manz MG, Miyamoto T, Akashi K, Weissman IL (2002) Prospective isolation of human clonogenic common myeloid progenitors. Proc Natl Acad Sci USA 99: 11872-11877.

31. Hao QL, Thiemann FT, Petersen D, Smogorzewska EM, Crooks GM (1996) Extended long-term culture reveals a highly quiescent and primitive human hematopoietic progenitor population. Blood 88:3306-3313.

32. Bhatia M, Wang JC, Kapp U, Bonnet D, Dick JE (1997) Purification of primitive human hematopoietic cells capable of repopulating immune-deficient mice. Proc Natl Acad Sci USA 94:5320-5325.

33. Larochelle A, et al. (1996) Identification of primitive human hematopoietic cells capable of repopulating NOD/SCID mouse bone marrow: Implications for gene therapy. Nat Med 2:1329-1337.

34. Majeti R, Park CY, Weissman IL (2007) Identification of a hierarchy of multipotent hematopoietic progenitors in human cord blood. Cell Stem Cell 1:635-645.

35. Dick JE, Bhatia M, Gan O, Kapp U, Wang JC (1997) Assay of human stem cells by repopulation of NOD/SCID mice. Stem Cells 15(Suppl 1):199-203; discussion 204-207.

36. Haley PJ (2003) Species differences in the structure and function of the immune system. Toxicology 188:49-71.

37. Mestas J, Hughes CC (2004) Of mice and not men: Differences between mouse and human immunology. J Immunol 172:2731-2738.

38. Rozemuller $\mathrm{H}$, et al. (2004) Enhanced engraftment of human cells in RAG2/gammac doubleknockout mice after treatment with CL2MDP liposomes. Exp Hematol 32:1118-1125.

39. Takenaka K, et al. (2007) Polymorphism in Sirpa modulates engraftment of human hematopoietic stem cells. Nat Immunol 8:1313-1323.

40. Takizawa H, Manz MG (2007) Macrophage tolerance: CD47-SIRP-alpha-mediated signals matter. Nat Immunol 8:1287-1289.

41. Jaiswal S, et al. (2009) CD47 is upregulated on circulating hematopoietic stem cells and leukemia cells to avoid phagocytosis. Cell 138:271-285.

42. Chao MP, et al. (2010) Anti-CD47 antibody synergizes with rituximab to promote phagocytosis and eradicate non-Hodgkin lymphoma. Cell 142:699-713.

43. Brehm MA, et al. (2010) Parameters for establishing humanized mouse models to study human immunity: Analysis of human hematopoietic stem cell engraftment in three immunodeficient strains of mice bearing the IL2rgamma(null) mutation. Clin Immunol 135:84-98.

44. Poueymirou WT, et al. (2007) Fo generation mice fully derived from gene-targeted embryonic stem cells allowing immediate phenotypic analyses. Nat Biotechnol 25: 91-99. 